\title{
Study on Consumer Behavior of Long Stay Tourist in Summer Resort Zhou Gang ${ }^{1,2, a}$
}

$\left({ }^{1}\right.$ Geography \& Tourism College of Chongqing Normal University, Chongqing, 400047;

${ }^{2}$ Economics \& Business Administration School of Chongqing University, Chongqing, 400030) ahappy_gun@163.com

Keywords: Long Stay Tourist in Summer Resort; consumer behavior; pre-purchasing behavior; consuming behavior; post-purchase evaluation.

\begin{abstract}
Long Stay Tourism is developed rapidly in recent years, and it is a kind of special interest tourism product and new pension model. Long Stay Tourism in Summer Resort (LSTSR) is most typical. In this paper, the consumers of Long Stay Tourism in Summer Resort are taken as the research object, the investigation methods such as questionnaire, depth interview and literature reference are taken in consideration, the pre-purchasing behaviors are focused, the purchasing \&consuming behaviors are researched, and the post-purchase behaviors are evaluated. The conclusions can provide the perfect decisions and scientific basis for the development of product, the improvement of service facilities, and the promotion of product and it can be used for formulating the strategy of market development.
\end{abstract}

\section{Introduction}

The consumer behavior is defined as the action of receiving, consuming and disposal of products and service for people. A whole consumer behavior usually has to go through several stages, such as problems recognition, information collection and evaluation, purchasing decision, and post-purchase evaluation ${ }^{[1-2]}$.

Long Stay Tourism is defined as: the elderly (55 years and above) do not work, settle down and emigrate for the purpose of travel, the temporary residence, and tour activities in the form of providing for the aged non-locally, and the Long Stay Tourism is combined with pension service and tourism activities together organically. It is a kind of new type of special tourism product; it is also a kind of the new pension mode. Long Stay Tourism is developed rapidly in China in recent year, and its forms are complex and multiple. With the change of seasons and climates, old people choose the more comfortable place for leisure supporting, which is the most typical form, namely Long Stay Tourism in Summer Resort (LSTSR) and Long Stay Tourism in Winter Resort (LSTWR). This paper mainly focuses on Long Stay Tourism in Summer Resort (hereafter referred to as LSTSR).

LSTSR has the following several representative models: (1) The destination depends on the city, it is often located within the city or suburbs, such as Geleshan Mountain and the Jinyun Mountain in Chongqing city; (2) The destination depends on scenic spot, it is often located in the interior or surrounding of the scenic spot, such as Qingcheng Mountain in Sichuan province. (3) The destination is mix of above two typical characteristics, such as Dianchi Lake Tourist Resort in Yunnan province. (4) The destination is not relying on the city, nor relying on the scenic spot, it is only relying on their own unique climate and good ecological environment. This kind of destination appears mostly in the form of rural tourism, which is relatively common in China, such as Jiuba town in Guizhou Province.

In this paper, Long Stay Tourists in Summer Resort are taken as the research object, and the consumer behaviors are analyzed. The conclusions can provide the scientific basis for the development of product, the improvement of service facilities, and the promotion of product, and it can be used for formulating the strategy of market development.

According to the stages consumer behaviors, combining with the actual condition of LSTSR, the three parts including pre-purchasing behavior, purchasing \&consuming behavior and post-purchase behavior are researched. Meanwhile, LSTSR is developing and changing, it is difficult to conclude and evaluate all types of consumer behavior completely. Therefore, case study is taken as the main research method, and the typical case is researched comprehensively in depth study. And the summary is obtained, which reveals the general law of consumer behavior. On the basis of the actual situation of domestic development, this paper selects Jiuba town in Guizhou Province as the 
object of questionnaire integrated with questionnaires and interviews of Gele Mountai, Jinyun Mountain, Wuling Mountain and Huangshui town in Chongqing city, Dianchi Lake Tourist Resort in Yunnan province, Qingcheng Mountain in Sichuan province from 2006 to 2014 year. The common part of consumer behavior characteristics around the different areas are extracted and analyzed in accordance with the data in Jiuba town. While the inconsistent parts of consumer behavior characteristics are extracted and analyzed in accordance with the data from other case study destination. The following analyzing data are come from Jiuba Town survey data if without special instructions.

\section{Basic Information of Long Stay Tourism Consumer}

According to the age and sex, there is no significant gender difference for different group. Most of consumers are 55-69 years old, young elderly are accounting for 76.6\%, and the average age is 64.53 years old ${ }^{1}$. In terms of health, the people who participate in tourism activities have general good health status. But the majority of people have the chronic diseases, accounting for 81.5\%, the diseases are shown as hypertension, diabetes mellitus, common cerebrovascular disease, and tracheitis, etc. But this proportion is lower than Long Stay Tourism in Winter Resort(LSTWR) ${ }^{2}$. The old-age population of LSTSR is from the vast majority of city, consumers who come from suburban and rural are less, which is related to their economic income and ideas.

From the marriage and family structure situation, empty nest families (old people living without their children) account for half the proportion. In the meantime, the married couples who live with their children and other family members hold the great proportion (42.5\%).This part of the elderly usually take their grandchildren in the whole journey.

From the perspective of education background, the diploma degree of old-age population is generally not high, the majority is the junior high school education level or below. The people who have higher education are only $11.4 \%$. In terms of income and occupation, the incomes of old-age population are mainly concentrated in the 1500-2499 Yuan. The main occupations are shown as: enterprise general staff, the professional or technical personnel, and enterprises and public institutions management personnel.

\section{Research of Pre-purchasing Consumer Behavior}

\section{A. Information Channel}

According to the questionnaire results, we can find that $85.3 \%$ of the elderly learn about the current tourism destination introduced by relatives and friends. Only a small part of people know about the destination through the network, or the working/ traveling experience before. It shows that the marketing of tourism destination is still in the primary stage. It is mainly relied on word-of-mouth of tourists for recommending. With the development of LSTSR, lots of destinations begin to promote themselves fixed time and fixed location in the tourist origin, in order to influence consumer behaviors. However, the network information and resources of tourism destination are lack in the present Internet age, the older consumers depend less on the network when they obtain information.

\section{B. Way of Traveling}

Most visitors select the self-service travel way (97.7\%), including taking the bus, driving their own car, shuttled by the relatives and friends. Visitors who join a tour group via their work units, travel agencies or old-age care institutions are very few. In the destinations with less development, such as Jiuba town in Guizhou province, Wuling Mountain in Chongqing city, etc., the travel agencies have not involved in these fields. While in the destinations with high development, such as

\footnotetext{
${ }^{1}$ It is generally thought that the old man from 60 to 69 years old called the young aged people, the old man from 70 to 79 years old are called the middle aged people, the old man 80 years and above are called the Advanced aged people.

${ }^{2}$ The research results in Hainan in 2007 show that $91.3 \%$ of long stay tourists in winter resort have chronic diseases, and health \&recuperation is the main purpose, treatment of disease is also one of its purpose.
} 
Dianchi Lake Tourist Resort in Yunnan province, the travel agency is also very minor as way of travel.

Most long stay tourist have typical characteristics of traveling in groups, of which more than half of the elderly travels only with their family, $20 \%$ elderly people travel with their friends or colleagues, and $20 \%$ elderly people travel with both family and friends or colleagues.

\section{C.Sources of Funding}

The vast majority of the elderly use self financing for LSTSR (96.8\%) based on the generous pensions, and few people rely on their children, relatives and friends.

\section{Research of Purchasing \&Consuming Behavior}

\section{A. Analysis of Cost}

In the whole tourism process, more than $98.4 \%$ of the aged think that cost for catering \& accommodation is the first expenditure, $63.6 \%$ of the old people hold that transportation cost is the second expenditure, and $71.1 \%$ of the elderly deem that shopping cost including daily necessities, daily consumables and tourism souvenirs etc. is the third expenditure. According to the survey data of Jiuba town, more than $95 \%$ of the elderly spend less than 2000 yuan, nearly $60 \%$ elderly spend 1000-1499 yuan on the whole journey. The old tourists cost for 1273.83 yuan a month in average.

\section{B.Analysis of Temporal and Spatial Distribution}

According to survey of Jiuba town, arrival time which the elderly reach the destination is June 5 th as the earliest time, and departure time is the late September 15th. 57.3\% of old-age population arrive at the destination from late June to early July. Taken the Jiuba as example, it has targeted Chongqing urban residents as the primary customers. In late of June, and in early July, Chongqing has entered the summer, the temperature is higher. However, in the Jiuba Mountain, the climate is cool, and its advantage of air temperature is highlighted. Besides, late of June, and in early July, the summer holidays for the middle and primary school students start, the aged who need to take care of the third generation tend to take their grandchildren to the destination together. Relatively speaking, return time is more concentrated, more than $50 \%$ of the elderly would choose to get back before September. And more than $90 \%$ of the elderly will return to the origin before September 10 th. The climate gets cool in the origin, and climate advantage is not obvious in the destination, which is the main reason of leading to return migration. In the meantime, a lot of the middle and primary schools begin in late of August, and in early September, the aged people have to return and take care of their grandchildren.

According to the related data in 2006 in Kunming, the shortest resident time is half a month, the longest resident time is half a year. Most of tourists stay in the destination in a relatively shorter time, and their sightseeing purpose is very strong. The data surveyed in Jiuba shows that the shortest resident time is a month, the longest resident time is three months, the average resident time is 59.87 days, and most of the elderly have leisure and vacationing purpose.

Long stay tourists usually take leisure and tourism activities in the destination and surrounding areas. Centered on this place, their travel distance is at most 30 kilometers, usually 5 kilometers. During tourism period, the farthest activities area of long stay tourist in Jiuba town is Tongzi county city, and the activities area of long stay tourist in Kunming rarely go beyond the range of the main urban area.

\section{C.Analysis of Tourism Purpose}

No doubt, the main purpose of the LSTSR is avoiding the oppressive summer heat, in addition to this purpose, others purposes for various types of tourism destination are different. Based on the scenic spots (or based on both the city and scenic spots), destination of the LSTSR is selected, and the tourists have sightseeing and vacationing purpose. The survey reveals that the main purposes of long stay tourist in Kunming are avoiding summer heat, health \&recuperation, sightseeing and leisure \&vacationing. Among these purposes, avoiding summer heat is accounting for $66.9 \%$, health \&recuperation is accounting for $70.8 \%$, sightseeing is accounting for $50.6 \%$, and leisure \&vacationing is accounting for $46.8 \%$. As for as the rural tourism destination depending on the climate and environment, the main purpose of the tourists is avoiding summer heat and other 
purposes are relatively minor, such as leisure \&vacationing, health \&recuperation and sightseeing, etc, which proportion is less than $20 \%$. In addition, in the destination of the city or its suburbs for LSTSR, the tourists may also visit friends and relatives, and it is confirmed from the interviews in Chongqing city for long stay tourists.

\section{D.Analysis of Tourism Demand Factors}

\section{a .Accommodation}

Long stay tourists are different to all parts of the country; they choose the destination according to local conditions. Take the rural tourism destination as the example, the farmhouse, rental housing and the own purchased housing are the most important selections. In the Huangshui town of Chongqing city and the Jiuba town of Guizhou province, the vast majority of the elderly population select farmhouse tourism with all the accommodation and diet, in the Qingcheng mountain of Sichuan province, long stay tourists not only select the farmhouse as the accommodation, but also select the long-term rent house (20 or 50 years) or the purchase house of their own as the accommodation. In the city and suburb destination, local apartment for the elderly (or nursing homes), sanatoriums, vacational village, rental housing, hotels and other various types of accommodation facilities are equipped. For instance, nearly $70 \%$ long stay tourists in Kunming city choose senior apartment or nursing homes for accommodation.

\section{b. Catering}

In the pension institutions such as farmhouse, apartments, nursing homes for the elderly etc., the elderly would generally choose tourism form equipped with accommodation and diet, only a few tourists consider their individual needs, they take the "cook their own" or "social restaurants" for diet. The elderly consumers with rental housing (long or short rent) and the purchase housing usually cook for themselves. Some hotels or resorts generally do not provide cookware, also do not provide catering (or offer price is very expensive), the tourism consumers usually choose the social restaurant to take meals.

\section{c. Transportation}

As far as the external transport is concerned, the traffic forms have no essential difference between the long stay tourists and general senior tourists, but during staying in the destination, long stay tourists usually use the local traffic system.

d. Travel

Under the normal circumstances, long stay tourists choose and visit the high level destinations, but don't miss some of the lower level destinations. The tourist spots with their own special characteristics, which is suitable for the older people's own taste, would be selected as the tourist destination, especially the scenic spots for free is very popular. Long stay tourists usually take the nodes shaped tourist routes, the temporary residence is taken as a stronghold, the half-day tour, one-day tour or several days tour can be carried out to different directions. In the Jiuba town, long stay tourists generally visit all the low level scenic spots, they will choose to visit the small town, and they may choose to go to the farther Loushanguan Scenic Spot and Zunyi city for travel. Similarly, long stay tourists in Kunming city tend to visit the high level scenic spots such as Stone Forest, Expo Park, National Village, but they also do not abandon the free scenic spots such as the Dianchi Lake, Green Lake Park, etc. and the low level scenic spots such as the Qiongzhu Temple, Heilongtan Park, and so on.

\section{e. Shopping}

The shopping in the course of LSTSR consists of two parts: daily shopping and tourist shopping, the behavior of daily shopping is similar to the local residents' behavior, they make full use of local farmers markets, supermarkets or shopping malls to buy necessary daily articles. On the other hand, the old tourists stay in the destination for the longer time, and they know the local tourism commodity very well, moreover, they don't have strong interest in tourism shopping. Hence, the number of tourism shopping is not much, and the pertinence is strong, what the old buy is mostly the local famous native products.

\section{f. Entertainment}


The leisure life of elderly people during long tourism is monotonous, usually by watching TV or chat for entertainment. Most reception units have not arranged recreational and sports activities, which mainly rely on the elderly own to organize themselves and carry out the entertainment activities or outdoor sports activities.

\section{g. Medical Service}

The destination of the city or its suburbs for LSTSR usually have good medical facilities and service, such as Dianchi Lake Tourist Resort in Kunming city and Gele mountain in Chongqing city, these tourist destinations can provide better conditions for the elderly. But for the destinations far away from the city, the medical facilities are still in poor conditions, such as the Jiuba town, there is only a small hospital, and the drugstores are also less across this destination. The relevant departments cannot make underlying medical service available to the tourists, if there are serious illnesses or hospitalizations, the old tourists need to be transferred to the county for treatment.

\section{h. Other Demand Factors}

At present, the elderly people of long stay tourism can usually participate in certain learning and training in the city destination, through learning and training, the growth of knowledge is acquired. It also can rich life, edify sentiment, and promote health. However, due to the lack of conditions in most of rural destination, elderly people have not the concentrated learning and training opportunities, and even the read paper and Internet access cannot be realized.

In the meantime, the insurance service of LSTSR is relatively poor, the consumer's own insurance consciousness is weak. The Jiuba's long stay tourists can enjoy group insurance, which may provide a certain guarantee of accidental injuries. However, the most basic accident insurances are not equipped in the Wuling Mountain in Chongqing city, which can cause certain hidden dangers and pose some serious safety hazards to the elderly themselves, the business enterprise, even the industry.

The psychological consultation service is very important service for the old people. Because of the current domestic limited conditions, the older consumers haven't experienced this special service yet.

\section{Research of Post-purchase Consumer Evaluation}

After the consumers buy the products, by means of using or consuming what they purchase, they test their buying decision, measure whether the buying decisions are right, and determine the degree of satisfaction as a future purchase decision reference ${ }^{[3]}$.

The hardware and software conditions in various types of destination are different, and the consumer mentalities and expectations also differ in thousands of ways, so it is difficult to carry out a unified evaluation. Jiuba town is taken as example below, and analysis and summary of this typical case are analyzed in order to reveal the common rule of long stay consumers' evaluation.

The questionnaire survey and assessment of consumers are implemented, the mean analysis is taken, and the results are concluded in Table $1^{3}$.

According to the results as above, the satisfaction scores are converted into centesimal system, if the scores are more than 70 points, it is satisfied, if the scores are between $60-70$ points, it is general. If the scores are 60 points below, it is not satisfied. Namely, the indexes with the score of the 3.5 points and above are the satisfactory items, the indexes between 3-3.5 points are general items, the indexes blow 3 points are dissatisfactory items.

According to the statistical results, the satisfactory indicators have 5 items (climate and environment, accommodation, catering, surrounding ecological environment and other residential environment), the general indicators have 3 items (travel \&tourism activity, tourist shopping), the dissatisfactory items have more than 10 items, such as daily shopping convenience degree, daily shopping richness, daily traffic, tourism traffic, entertainment, spiritual consolation, price, learning

\footnotetext{
${ }^{3}$ The questionnaire adopts five-point Likert scale where 5 means "very satisfied", 4 means "satisfied", 3 means " modest or not clear" , 2 means "dissatisfied" and 1 means "very dissatisfied".
} 
and training, rehabilitation care, water quality, medical facilities, these dissatisfactory items are mostly related to the old people's themselves life.

At the same time, according to the survey of Guizhou province, the most important indicators to long stay tourists are water quality, climate environment, the surrounding ecological environment, medical facilities, and daily traffic. Therefore, in order to meet the needs of tourists fully, the important projects such as water quality, medical treatment and daily traffic should be strengthened, and the construction should be improved.

Table 1 Tourist Satisfaction Analysis in the LSTSR Destination (Jiuba town, Guizhou province)

\begin{tabular}{|c|c|c|c|}
\hline Evaluation Item & $\begin{array}{c}\text { Mean Value of } \\
\text { Satisfaction }\end{array}$ & Evaluation Item & $\begin{array}{c}\text { Mean Value of } \\
\text { Satisfaction }\end{array}$ \\
\hline Climate and environment & 4.25 & Daily traffic & 2.82 \\
\hline Accommodation & 4.05 & Tourism traffic & 2.73 \\
\hline Catering & 3.86 & Entertainment & 2.72 \\
\hline $\begin{array}{c}\text { Surrounding ecological } \\
\text { environment }\end{array}$ & 3.74 & Spiritual consolation & 2.71 \\
\hline Other residential environment & 3.66 & Price & 2.59 \\
\hline Tourist shopping & 3.10 & Learning and & 2.52 \\
\hline Travel \&tourism activity & 3.09 & Rehabilitation care & 2.35 \\
\hline Daily shopping convenience & 2.99 & Water quality & 2.04 \\
\hline Daily shopping richness & 2.99 & Medical facilities & 1.57 \\
\hline Overall Satisfaction Degree & \multicolumn{3}{|c|}{} \\
\hline
\end{tabular}

According to the survey, the mean value of overall satisfaction degree is 3.76 by the five-point Likert scale, the tourists are generally satisfied with the destination. More than $60 \%$ old people are willing go to the destination for long stay tourism once again. Nearly $30 \%$ of the tourists are not sure, and only less than $10 \%$ visitors are not willing to get to the destination or carry out long stay tourism activities any more. After the basic recognition of a destination, the conclusion is sure, as long as the facilities and conditions don't dramatically change, such as climate change, environmental degradation, soaring prices etc., most elderly consumers would choose once again to the destination of LSTSR, which also reflects the more conservative in the aged tourism consumers.

\section{Conclusion}

Compared with the average tourism consumer behavior, long stay tourist in summer resort shows its own unique behavior characteristics in the course of pre-purchasing, purchasing \&Consuming, and post-purchasing. Among them, pre-purchasing is mainly manifested in the information channels, way of traveling and sources of funding; purchasing and consuming is mainly embodied in cost, temporal and spatial distribution, purpose, demand factors(Accommodation, Catering, Transportation, Travel, Shopping, Entertainment, Medical Service, etc.); post-purchasing mainly reflects on the consumer satisfaction evaluation.

Through the above analysis of consumer behavior, we can see that: on the one hand, domestic $t$ destination of LSTSR has several big problems in business ideas, facilities, and operation \&management and so on., which imposes large restrictions on consumer behavior, on the other hand, the characteristics of long stay tourists can put forward new and higher requirements for the improvement of the above several aspects. The urgently problem at present is to develop the product of LSTSR, improve service facilities, and implement marketing strategy and tactics.

\section{Acknowledgments}

This study is supported by Humanity and Social Science Youth Foundation of Ministry of Education of China (Grant No. 12YJCZH311), the Foundation of Chongqing Normal University (Grant No. 10XWQ09). 


\section{References}

[1] Zhu Shu. Consumer Behavior [M]. Shanghai: East China University of Science and Technology Press, 2009:3.

[2] Li Wurong. Study on Consumer Behavior and Marketing [J]. Social Science Journal, 1999 (2) : 53-58.

[3] Ye Min, Zhang Bo, Ping Yuwei. Consumer Behavior [M]. Beijing: Beijing University of Posts and Telecommunications Press, 2007:359. 